\title{
Language specific narrative text structure elements in multilingual children
}

\author{
Heike Tappe and Agness Hara \\ Linguistics Programme, University of KwaZulu-Natal, South Africa \\ E-mail: tappe@ukzn.ac.za
}

\begin{abstract}
The investigation of narrative skills in children is significant in many respects; amongst other things, narratives can yield information about a child's use of decontextualised, literate language features (Curenton and Justice 2004) while simultaneously providing access to the child's level of competence concerning narrative-specific aspects. Narrative abilities have been linked to literacy development and academic achievement (Dickinson and Tabors 2001) and are often used to predict language progress (Botting, Faragher, Simkin, Knox and ContiRamsden 2001). Moreover, narrative skills constitute an area of verbal language development in which delays are difficult to compensate (Girolametto, Wiigs, Smyth, Weitzman and Pearce 2001, Manhardt and Rescorla 2002). However, in multilingual settings the assessment of narrative skills cannot be restricted to language proficiency measurements in each of a child's languages. Rather, this assessment needs to include "linguistic descriptions of ethno-linguistic discourse patterns (contrastive rhetoric)" (Barnitz 1986:95) in order to assess the roles which cultural knowledge and language-specific narrative text structure elements play in the development of narrative skills in multilingual children. This article discusses the necessity to identify such language-specific elements of story structures. Empirical findings are presented which illustrate that 10- to 12-year-old children from Malawi exhibit narrative practices while they retell visually and aurally presented stories. It appears that these narrative practices are influenced by African folktales. The children's retellings in both Chichewa and English cannot simply be measured by canonical narrative text structures commonly used in academic settings. The global significance of such a discussion is reflected by a growing concern that academic success may be compromised by a misalignment between the narrative practices in a child's primary language(s) and the narrative practices in a respective language of teaching and learning (e.g. Makoe and McKinney 2009, Souto-Manning 2013).
\end{abstract}

Keywords: language-specific narrative text structure, story grammar, narrative development, multilingualism, African folktale 


\section{Introduction}

Neither the concept of 'story grammar' nor the related concept of 'story schema' are homogeneous. Moreover, both theoretical notions have undergone a number of revisions over time and the mere idea of mental representations has come under fire from the antirepresentationalist faction in the cognitive sciences (e.g. Brooks 1991, Clark 2001). However, the understanding prevails that "good", comprehensible narratives adhere to an underlying narrative text structure: listeners evaluate the quality of narratives against the background of an intuitively "good" story structure (which should not be too predictable but which should also not be a random series of events $)^{1}$ and educators use the concept of a 'canonical narrative text structure' to both teach narrative structure to children as well as to assess children's narrative skills in educational contexts. Moreover, the concept of a 'canonical' narrative text structure is widely used for comparisons of educational systems, for example, by measuring narrative comprehension in school children from different areas, countries and continents.

In this article, we hypothesise that children who are not primarily exposed to canonical narrative text structures during socialisation may exhibit somewhat "non-canonical" text structure elements in their narratives. Consequently, we argue that language proficiency measurements need to take into account a child's "narrative socialisation"; in other words, teaching and assessment of narrative text structure needs to be based on "[...] linguistic descriptions of ethnolinguistic discourse patterns (contrastive rhetoric)" (Barnitz 1986:95).

\subsection{Previous research on narrative text structure: An overview}

Narrative text structure has largely been investigated within three consecutive phases of research (Olson and Gee 1988). Early research in the first phase of investigation developed a taxonomy of narrative elements which underlie story construction. This research then focused on finding empirical evidence for its psychological "realness" (e.g. Mandler and Johnson 1977, Rumelhart 1975, Stein and Glenn 1978, Thorndyke 1977). This kind of research involved the investigation of narrative skills in adults and children specifically, and has posited two classes of theoretical structures known as "story grammars" and the closely related "story schemas" (Mandler 1983, Shapiro and Hudson 1991, Soodla and Kikas 2010). These hypothetical mental representations ${ }^{2}$ have been assumed to provide a theoretical account of the structural organisation that causes one instance of discourse to be perceived by an addressee as a coherent narrative, while an alternative arrangement of the same set of utterances or sentences may be judged to be utterly incoherent by the same addressee. Narratives that adhere to what is widely perceived as a "canonical" narrative text structure (or story grammar) have been found to lead to greater ease of processing, better understanding and better recall than narratives that are perceived to deviate from such a structure (Bower, Black and Turner 1979; Mandler 1978, 1984; Mandler and DeForest 1979; Mandler and Johnson 1977; Stein and Nezworski 1978).

\footnotetext{
1 "Skillful story tellers will be able to make an accurate assessment of the knowledge shared between themselves and their listeners, and to manipulate that knowledge in the interests of constructing a tale that is both recognizable and original" (Parke 2001:401).

${ }^{2} \mathrm{Cf}$. section 2 for a more detailed discussion of the differences between the two types of representations.
} 
The second phase of research focused on the flexible use and complexity of narrative text structures. This was carried out by comparing the use of narrative text structures by different types of readers, as well as these readers' accessibility to these types of structures (e.g. Mandler and Johnson 1977, Ouellette, Dagostino and Carifio 1998, Stein and Glenn 1979, Whaley 1981). This research phase generated findings of developmental differences across various groups of school-age readers.

The third phase of research currently centres around the question of whether it is possible to teach the components of story structure, which were identified in phase one and verified in phase two, in order to improve reading comprehension (e.g. Carnine and Kinder 1985, Dimino, Gersten, Carnine and Blake 1990, Fitzgerald and Spiegel 1983, Gardill and Jitendra 1999, Griffey, Zigmond and Leinhardt 1988, Gurney, Gersten, Dimino and Carnine 1990, Idol and Croll 1987, Short and Ryan 1984, Singer and Donlan 1982). Several authors (e.g. Gersten, Fuchs, Williams and Baker 2001, Fagella-Luby, Schumaker and Deshler 2007) emphasise that while students' basic academic skills may have improved after they were taught an awareness of story structures, research in this area is, as yet, too sparse to be conclusive.

Moreover, there is surprisingly little discussion of the significance of narrative text structures in multicultural and multi-linguistic societies even though cross-linguistic research on narrative text structures clearly reveals that, despite a number of supposedly universal story features, there are striking differences between language-specific rhetorical styles. These differences are grounded, one the one hand, in varying lexicalisation patterns and structural differences across languages and, on the other hand, in diverging cultural narrative practices (Slobin 2004:219, 222). These differences might jeopardise both intra-national assessments of literacy components across different language groups as well as international comparisons of such skills with regard to diverging cultural narrative practices. Bechger, van Schooten, de Glopper and Hox (1998:101) note that the validity of measurements of literacy skills within one nation, and the comparability of these measurements across nations, may be conflicting aims.

\subsection{Research objectives}

Against the background outlined in section 1.1, this article argues that a discussion of linguistic variability of narrative text structures is necessary on various levels in multilingual societies. It is necessary in order to not only preserve cultural and linguistic diversity, but also to support students who find themselves in educational environments in which their cultural and linguistic practices are misaligned with the language(s) of teaching and learning.

Gersten et al. (2001) present evidence from a number of research projects which indicates the importance for students to be aware of underlying story structures. This awareness may not only improve their basic academic performance, but may also lead to higher-order thinking. This very positive assessment of the role of narrative text structure in text comprehension is in line with Kintsch's (2004) study which indicates that students' understanding and employment of text structure positively influences their text comprehension. Hence, in order to aid students in the conceptual understanding of (narrative) texts, it seems to be recommendable that instruction should explicitly introduce narrative text structure.

The possibility of teaching a canonical story grammar model (or a variant thereof) to improve reading comprehension has been widely researched (e.g. Carnine and Kinder 1985, Dimino et 
al. 1990, Fagella-Luby et al. 2007, Fitzgerald and Spiegel 1983, Gardill and Jitendra 1999, Gersten et al. 2001, Griffey et al. 1988, Gurney et al. 1990, Idol and Croll 1987, Short and Ryan 1984, Singer and Donlan 1982). While this kind of research has led to the development of a variety of pedagogical concepts, the question of how well a canonical story grammar model is suited for the development of literacy and text comprehension in multilingual and multicultural educational settings is only just beginning to gain momentum.

In light of this concern, we argue that language- and culture-specific differences may not always be easily reconcilable with Stein and Glenn's (1979) contention that a linguistically-complete narrative consists of the seven logically-sequenced story grammar elements that they identify (see Table 1). Moreover, even Anderson and Evans' (1996) canonical story grammar model which is based on a larger body of previous research - might not be as canonical as is widely assumed. While we are aware of a large body of comparative research on narratives in a multitude of languages, we want to emphasise that there is much room for improvement concerning three major aspects. Firstly, for the most part, existing research does not concentrate on macro-structural differences between texts produced in different languages, while a huge number of language families are under-represented in or absent from such research. Secondly, while language- and culture-specific differences between narrative text structures may have been noted amongst researchers, such an insight does not seem to have led to a widespread acknowledgement and emancipation of seemingly "non-canonical" narrative text structures in educational settings (e.g. Souto-Manning 2013 on the latter aspect).

While our discussion is based on research results from around the world, our focus is on the African context. Our main objectives are: (i) to identify and discuss current variants of narrative text structures; (ii) to emphasise the need for investigation of language-specific narrative text structures by using examples from African languages such as isiZulu, Northern Sotho and Chichewa, and (iii) to illustrate how the outcomes of such comparative analyses may be implemented in educational contexts in order to promote literacy and text comprehension in multilingual and multicultural students. We argue that it is necessary for students and educators alike to be able to discuss similarities and differences between languages not only with respect to their varying lexical and morpho-syntactic features, but also with respect to why, how and where narrative practices diverge across languages and cultures. This type of curriculum may help to empower students who are exposed to narrative text structures during socialisation which are not endorsed in their academic environment.

\section{Canonical narrative representation}

The idea that mental representations of narratives (or "story schemas"), which reflect recurrent features of stories, might be psychologically "real" rests on the assumption that an audience will perceive a difference between a coherent narrative and a (re)collection of disconnected events. Story schemas are not identical to story grammars; story schemas are domain representations, whereas story grammars are representations of text containing information about global (macro-structural) features of text, which interact with local (micro-structural) text features. As such, story grammars are conceived as formal rule systems which are employed to describe regularities in the structure of stories (e.g. Mandler 1982:207). Van Dijk and Kintsch (1983) integrate macro- and micro-structural features into one representation they call a "textbase". In the current research, we adopt Van Dijk and Kintsch's (1983) perspective and include micro-structural features in our discussion of narrative text structures while the main 
focus remains on "classical" story grammar elements as identified by Stein and Glenn (1979) and summarised in Table 1.

Table 1. Story grammar according to Stein and Glenn (1979), summarised by Griffith, Ripich and Dastoli (1987:541)

\begin{tabular}{|l|l|}
\hline \multicolumn{1}{|c|}{ Element } & \multicolumn{1}{|c|}{ Definition } \\
\hline Setting & $\begin{array}{l}\text { The spatial and/or temporal location where story events } \\
\text { take place; the introduction of the main characters, the } \\
\text { protagonist and the spatio-temporal context. }\end{array}$ \\
\hline Initiating event & $\begin{array}{l}\text { An event which typically introduces a state-of-affairs } \\
\text { that is 'out of the ordinary' for the protagonist, i.e. the } \\
\text { occurrence that influences the main character to action. }\end{array}$ \\
\hline Protagonist's internal response & $\begin{array}{l}\text { An affective or emotive reaction to the initiating event. } \\
\text { Indicates the thought(s), feeling(s) of the protagonist in } \\
\text { response to the initiation event; may include an } \\
\text { interpretation of the event, formulation of a goal and } \\
\text { serves to motivate action. }\end{array}$ \\
\hline Plan & $\begin{array}{l}\text { A set of intentions formed in the mind of the person } \\
\text { affected by the initiating event. Indicates the intended } \\
\text { action of the protagonist (the announcement of the } \\
\text { intended action). }\end{array}$ \\
\hline Attempt & $\begin{array}{l}\text { The protagonist's effort to execute the plan. Indicates the } \\
\text { overt actions of the protagonist in pursuit of the goal. }\end{array}$ \\
\hline Consequences or outcomes & $\begin{array}{l}\text { The (non-)attainment of the goal, or other events that are } \\
\text { the result of the attempt. }\end{array}$ \\
\hline Resolution or outcome & $\begin{array}{l}\text { Any emotional or evaluative response by the protagonist } \\
\text { to the preceding chain of events. }\end{array}$ \\
\hline
\end{tabular}

Research on elements of story grammar was most prominent in the 1970s and 1980s when it generated a very large body of research (e.g. Labov 1972, Mandler and Johnson 1977, Rumelhart 1975, Stein and Glenn 1979, Thorndyke 1977). While there are differences between variants of narrative text structure models, they are remarkably similar overall. For example, most models agree that stories begin with a description of the setting, of characters, places and the backdrop of the narrative from which the narrative evolves ${ }^{3}$.

Based on an analysis of similarities and differences between a wide variety of different models of narrative text structure, Anderson and Evans (1996) streamlined Stein and Glenn's (1979) story grammar into the more concise Canonical Story Grammar Model presented in Table 2. This model has since been used in a wide variety of contexts, specifically to assess and evaluate narrative text structure in didactic contexts and for teaching text comprehension.

\footnotetext{
${ }^{3}$ However, cf. section 3 on less canonical narrative text structures.
} 
Table 2. The Canonical Story Grammar Model (CSGM) (Anderson and Evans 1996)

\begin{tabular}{|c|c|}
\hline Element & Definition \\
\hline Setting & $\begin{array}{l}\text { Introduction of the main character and description of the time, location } \\
\text { and/or social context of the story. }\end{array}$ \\
\hline $\begin{array}{l}\text { Beginning } \\
\text { Event }\end{array}$ & A cause which initiates a reaction or response from the main character. \\
\hline $\begin{array}{l}\text { Internal } \\
\text { Reaction }\end{array}$ & $\begin{array}{l}\text { An emotional response by the character which leads to the creation of a } \\
\text { goal. }\end{array}$ \\
\hline Attempt & An action from the character to achieve the goal. \\
\hline Ending & $\begin{array}{l}\text { (Non-) attainment of the goal by the character and/or the character's } \\
\text { reaction to the outcome and/or a moral. }\end{array}$ \\
\hline
\end{tabular}

Both Stein and Glenn's (1979) story grammar as well as Anderson and Evans' (1996) Canonical Story Grammar Model capture a widely shared, intuitive understanding of what a "wellstructured" narrative structure looks like. Feltis, Powella, Snow and Hughes-Scholes (2010) present one example of very recent research on child witness accounts of child abuse that demonstrates the importance of the presence of story grammar elements. The authors (2010:408) outline in the following quote how child witness reports, which are crucial for child abuse trials in the United States of America (USA), gain credibility if they contain story grammar elements in a sequential order, as in Tables 1 and 2:

The important role of story grammar is also demonstrated in studies showing the impact of this variable on listener judgements of the quality or believability of children's spoken narratives. Witness credibility is determined in part by the degree to which the witness' account is meaningful (Raskin \& Esplin 1991) and objective measures of narrative completeness using the story grammar framework have been found to predict quality ratings of meaningfulness. For example, Newman and McGregor (2006) showed that higher listener quality ratings with respect to the meaning of children's narratives were associated with an increase in the number of story grammar elements reported. Further, Schneider and Winship (2002) demonstrated that when length of the narrative is controlled for, adult lay persons perceive narratives that contain formal story grammar elements to be better quality (i.e., to maximise comprehension) than those where story grammar elements are omitted. Witness credibility, in turn, impacts jury decision making [...].

Moreover, the concept of a 'universally valid' canonical narrative text structure has gained validity through comparative research, such as the cross-cultural investigation of story recall conducted by Mandler, Scribner, Cole and DeForest (1980) which demonstrated an impressive degree of consistency across groups. Mandler et al. (1980) compared groups of schooled vs. unschooled Liberian participants as well as literate vs. non-literate participants and found no variation in narrative text structures across groups ranging in age from six to 50 years. In addition, the authors emphasise that, after hearing the same set of stories, the story recalls produced by the Liberian participants were structurally identical to recalls produced by 
American university students. On the basis of these data, Mandler et al. (1980) suggest that the kind of story schema they found across different populations may be a cognitive universal. As a consequence of the perception that we find a universal similarity in narratives across cultures and languages on a macro-structural level, research in the 1980s and onwards has primarily focused on the teachability of the type of narrative text structure identified as "universally" canonical (following Stein and Glenn 1979 as well as Anderson and Evans 1996). These types of narrative text structures have also been used globally in the assessment of narrative skill development.

In contrast, research on linguistic and cultural differences in narrative macro-structure is sparse; this is particularly the case with regard to research on learners who are exposed to multiple narrative text structures during their socialisation and for the resulting academic success of these types of learners.

\subsection{How universal is the canonical story grammar?}

There are several reasons why the Canonical Story Grammar Model (Anderson and Evans 1996), and variants thereof, is compelling. However, there are two reasons in particular which amplify one another and might be most influential: first, there is the possibility of a conflation of the three concepts, namely 'event structure', 'story schema' and 'story grammar/narrative text structure'. In the context of the current contribution, we are particularly interested in this aspect. The second possible reason is that globalisation seems to have caused a dominance of mainstream, predominantly Anglo-American narrative (text) structure (especially through electronic media like television and cinema), on the one hand, and a dominance of AngloAmerican ideologies in educational systems on the other.

\subsubsection{A possible conflation of event structure, story schema and narrative text structure (story grammar)}

In order to discuss the question as to whether there might be a conflation between event structure, story schema and narrative text structure, we need to disentangle the relationship between three different representations, namely the mental representation of an unfolding series of events (event structure), the representation of a "typical" narrative (story schema) and the representation of required story elements (narrative text structure or story grammar).

Event structures play a role in the pre-linguistic conceptualisation of the world. It can be argued that the world in which we navigate consists of complex and continuous activity. Different species "carve up" this continuous flow of activity and change in different ways. Within this view, events do not exist in the world as such but are created by a cognitive system. The human mind also "creates structured representations of events that capture abstract spatial, temporal, and causal information about the world" (Bungera, Papafragoua and Trueswell 2013:1). Event structures consist of concepts which represent the entities that participate in an event, conceptually or contextually salient characteristics of those entities, and, importantly, concepts of the relations among the event participants (Tappe and Habel 1998:2, Habel and Tappe 1999:3-4), as elaborated upon in the following quote by Bungera, Papafragoua and Trueswell $(2013: 1)$. 
The relations between event participants are defined in terms of conceptual/semantic features (e.g., motion, contact, causation, transfer) that facilitate generalization, allowing events to be grouped into classes on the basis of their event structure - that is, a schematic of the types of participants in an event (e.g., agent, causer, recipient) and the types of relations that hold among them (e.g. Jackendoff 1990; Pinker 1989; Rappaport Hovav and Levin 1998; Talmy 1985a, 2000).

The concept of a 'non-linguistic event structure' is akin to the more contemporary concept of a 'situation model'. In recent years, research in the cognitive sciences has established the significance of situation models (e.g. Zwaan and Radvansky 1998, Wyer 2004, Brownstein and Reed 2007). Situation models are mental representations of states of affairs which may (or crucially - may not) be conveyed in text (Cowley 2009 lists a number of cognitive domains in which situation models are used). Situation models have, however, mainly been discussed in relation to text comprehension: it has been found that they enable comprehenders to fill gaps in texts with meaningful information, infer information, mentally navigate through spatial and temporal spaces, enable recall and facilitate comprehension (see Zwaan and Radvansky 1998 for a review).

The prevalence of discussing event structure (or situation model) predominantly in the context of text comprehension might have led to a conflation between event structure and story schema, especially if the two distinct representations seem to be equated, as in the following explanation by Brewer (1984:3):

The event structure that underlies a narrative consists of a series of events ${ }^{4}$ arranged in temporal order with respect to some real or imaginary world. [...] These schemas that underlie narratives are presumably the same ones that are used to structure the observed actions of objects and people in the ordinary world (cf. Brewer and Dupree 1983; van Dijk 1975; Lichtenstein and Brewer 1980).

The "conflation problem" that we are discussing arises from such statements. While we concur with the view that textual representations (stories, texts, narratives, oral discourse, etc.) are obviously an important source for acquiring knowledge about possible worlds, including the world in which we live, we want to highlight that influential researchers in the field have defined story schema as being a mental domain representation that is acquired through exposure to a variety of stories (cf. e.g. Mandler 1982:207). Hence, story schema as a mental representation is conceptualised as being an abstraction over linguistic descriptions of events as presented in a large number of stories during socialisation. And since linguistic descriptions differ, the mental representations that are built from them may also differ. One important instance of such a difference is that event structure captures the chronological sequence of events while narrative text structure (story schema) captures the order in which events are presented in a narrative (see e.g. Brewer and Lichtenstein (1980:1) for a similar view). This difference has been highlighted as the so-called "linearization problem" (Levelt 1982) which

\footnotetext{
${ }^{4}$ We have simplified the issue here for the purpose of this discussion. However, many cognitive scientists assume that events have to be "construed" as they are often seen as entities which only exist in the mind of sapient beings and not as entities that exist "in the world" (cf. e.g. Pianesi and Varzi 2000:3, Habel and Tappe 1999:125-127).
} 
states that, with regard to language production systems, we have to decide how to organise events into a sequence for verbalisation.

As an alternative to treating event structure (situation model) and narrative text structure (story schema) as identical, we thus propose to differentiate between the two. Under this view the concept of 'story schema' needs to be redefined as an interface representation between event structure and narrative text grammar (see Figure 1). This idea is in line with similar proposals from D'Andrade (1995), Holland and Cole (1995), Malcolm and Sharifian (2002), Rice (1980), Sharifian (2001, 2002), Shore (1996) as well Strauss and Quinn (1997) who agree that schema theory enables a theoretical interface between cognition, culture and language. As a consequence, story schema is conceived as a domain-specific representation relating, on the one hand, to the representation of the real world or a fairy tale/science fiction/fantasy/etc. world and, on the other hand, to the representation of required story elements (narrative text structure or story grammar) at the actual textual level. This proposal seems to be preferable against the background that narratives often present events which take place in highly culture-specific possible worlds, following culture-specific dynamics ${ }^{5}$. It also captures the observation that individuals who have not had any exposure to stories during socialisation might not be able to organise an account of events into a coherent narrative but might still be well-equipped to reason about a series of events and to problem-solve by detecting and being knowledgeable about causal chains.

Ever since the concepts of 'story schema' and 'story grammar' were pioneered in the 1970s (Labov 1972, Mandler and Johnson 1977, Rumelhart 1975, Stein and Glenn 1979, Thorndyke 1977), researchers interested in narrative text structure have viewed story schema and narrative text structure (or story grammar) as different entities. Narrative text structure (or story grammar) is a procedural rule system which is employed to describe regularities in the structure of stories (Mandler 1982:207). Story schema, as explained in the previous section, is acquired through exposure to narratives and is an abstract, supposedly non-linguistic domain representation. The inter-relatedness of the two concepts has led to the understanding that the closer a particular narrative reflects a narrative text structure, which in turn is maximally similar to the underlying story schema, the better the quality of the narrative ${ }^{6}$. We do not contest this view. However, given the aforementioned risk of a conflation between story schema and event structure, we arrive at a situation where two things may happen: first, a narrative that best reflects event structure may be the most highly-rated. Second, we may ignore the possibility that there might be various story schemas relating to one event structure, some of which have culture-specific characteristics.

The differences between event structure, story schema and narrative text structure (or story grammar) can be illustrated through an example from Tannen (1980). She found that in

\footnotetext{
${ }^{5}$ Nonlinear narratives which deviate from the "canonical" schema are often perceived as "rambling" and "incoherent" by members of the dominant cultural paradigm (see section 2.1.2). We assume that the perceived "incoherence" is not only due to a language-specific narrative text structure (or story grammar) but also to a culture-specific story schema. This assumption needs more empirical support which we hope to supply in the future.

${ }^{6}$ Compare, for example, the following quote from Rand (1984:377): “Story schema also plays an important part in retrieval. To order recall, the reader follows the familiar framework of typical stories. The more a story conforms to an ideal structure, the better the recall (Mandler 1978)".
} 
children's retellings of the wordless "Pear Story" film7, American children recounted all and only the events in the story, which can be interpreted as an attempt to provide as correct and complete an account as possible of the presented events. Greek children, in contrast, perceived this type of approach to narrative re-telling as boring and unimaginative. Consequently, they developed little side-stories and character developments, which were not present in the film, to create an interesting story for their interlocutor, with little emphasis being placed on minor events that were contained in the movie but did not contribute to their storyline.

What this example illustrates is that both sets of children saw the same movie and, arguably, built up the same event structure representation from the movie which means that they probably would have been able to reason about the events unfolding in the film in the same way. Crucially, however, the Greek children seemed to have re-conceptualised the events into a Greek story schema while the American children's story schema seems to have been very much in line with the event structure. In the outcome, the Greek story schema and consequently the Greek narrative text structure (or story grammar) did not conform to the Anglo-American story schema and narrative text structure. However, it would seem that many researchers, language practitioners and parents the world over would agree that the American children's narratives were more "adequate" than those of the Greek children. Such an apparent "devaluation" of the Greek narratives might be motivated precisely by the conflation between event structure, story schema and narrative text structure in the dominant paradigm discussed earlier in this section. It seems to us that a conformity of narratives to an Anglo-American story schema, that is acquired by exposure to stories from this particular linguistic and cultural context, is widely assumed to be universal and hence the "norm".

However, as the example indicates, there are one-to-many mappings between event structure (situation model) and various story schemas (e.g. the Anglo-American and Greek story schemas in the previous example), and hence to a multitude of different narrative text structures (resulting in distinct classes of narratives). Figure 1 presents a schematic illustration which identifies the level of story schema as an interface level between event structure and narrative text structure.

\footnotetext{
${ }^{7}$ See https://www.youtube.com/watch?v=bRNSTxTpG7U.
} 
Figure 1. One-to-many mappings between event structure and story schema leading to various narrative text structures (story schemas) and infinite narratives (N1-N5 and beyond) which in turn define the formation of story schema (green arrow) via a feedback loop.

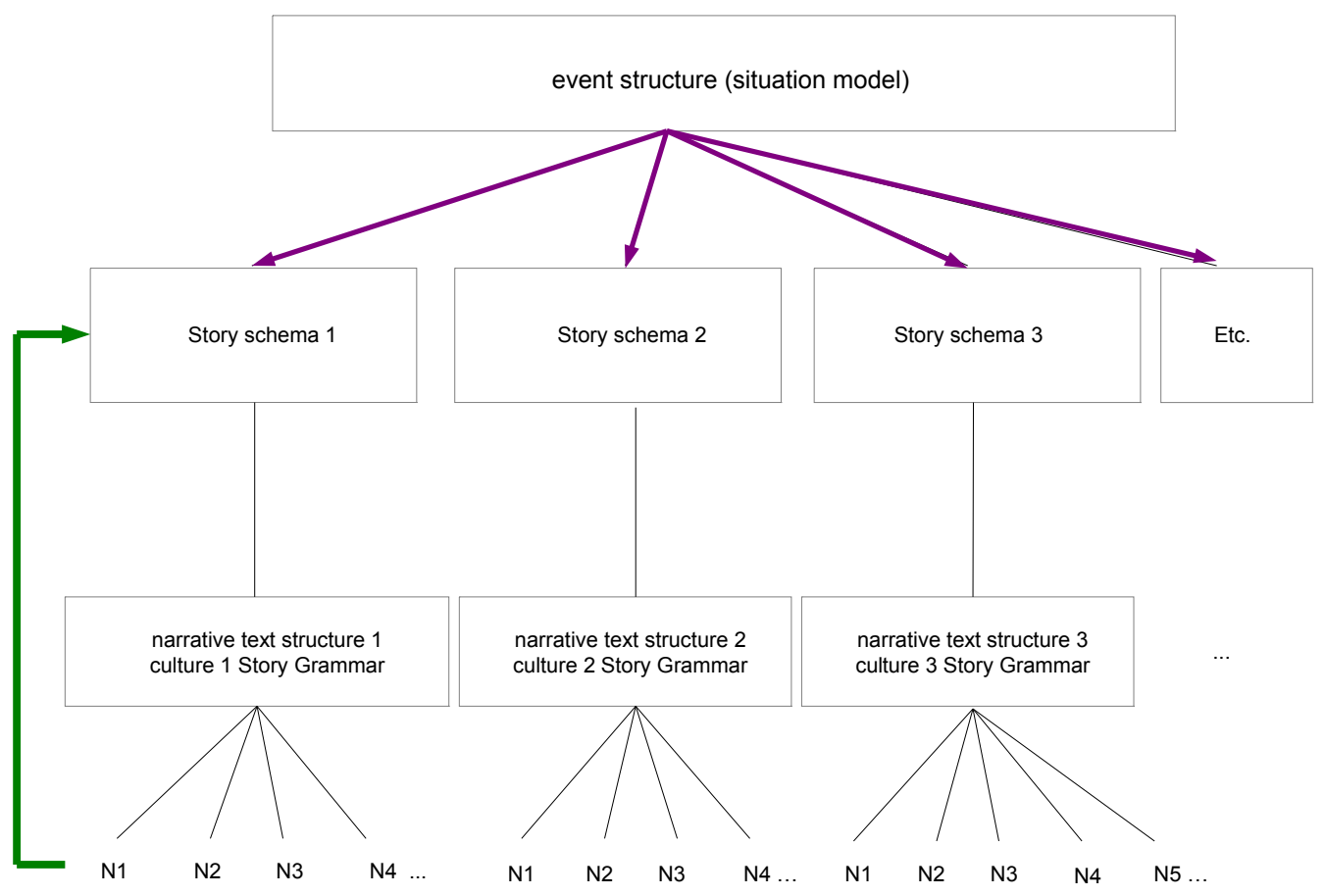

One-to-many mappings are evident, for example, in narratives elicited by using the aforementioned Pear Story short film (e.g. Chafe 1980) and Mayer's (1969) equally wordless "Frog, where are you?" picture book (e.g. Berman and Slobin 1994, Strömqvist and Verhoeven 2004). Both the short film and the book have been used to elicit large amounts of narratives from speakers with different language backgrounds ${ }^{8}$; these narratives demonstrate languageand culture-specific differences in narrative organisation which affect both micro- and macrostructural narrative features.

\subsubsection{The dominance of Anglo-American narrative text structure}

As suggested by Mandler (1982), story schemas are learnt and reinforced through the narratives we are exposed to during and after socialisation. However, in this era of globalisation, we are exposed to more and more of the same type of narrative due to the fact that our culture- and language-specific oral traditions are dwindling, and the more we are consuming the same type of narrative, the less accessible divergent types of narratives become. This habituating mechanism then has an impact not only on which narratives we are likely to consume and enjoy, but also on which narratives we perceive as being of high quality. Narratives conforming to mainstream schemas are more likely to be favourably assessed in academic contexts. As Westby, Moore and Roman (2002) point out, children who grow up with a narrative tradition

\footnotetext{
${ }^{8}$ It must be noted that, as of yet, these widely used elicitation tools have hardly been employed to elicit narrative text in African languages. However, both materials have been employed to elicit narratives from speakers of various age groups and speakers with a variety of medical conditions.
} 
that differs from mainstream narrative practice (like the children of the Keres, a Native American people) are likely to have low literacy scores which affect their academic performance. In the excerpt below, Westby et al. (2002:237) report on the Talking about Life Experiences and Stories (TALES) project which is aimed at addressing the misalignment between the narrative text structure in Keres tales and mainstream narrative text structure:

The project was initiated because tribal members were concerned about the poor reading performance of their students, whose reading scores are among the lowest in the state. Although the students learn to read words, they exhibit marked deficits in comprehension. It was hypothesized that at least part of the students' comprehension difficulty might be due to insufficient narrative skills, not only in mainstream English narratives, but also in Keres narratives. Tribal elders reported that with television, children were hearing fewer of the traditional stories in their homes. In addition, the oral discourse style and the content and structure of Keres narratives the children did hear were likely to differ from the narratives heard and read in school.

Similar observations have been made in other parts of the world, predominantly in the USA where more than $30 \%$ of all students are not Anglo-American but the majority of teachers are whites of European descent. Westby et al. (2002:238) state that previous research has mainly been concerned with "[...] how the collected narratives relate to the narrative demands in students' home culture as well as the mainstream culture. Some of this information is available regarding children from African-American and Hispanic backgrounds (Gee 1989; GutierrezClellen 1995; Hester 1996; Hyter and Westby 1996; Labov and Waletzky 1967; Shuman 1986), but very little is available on children from other cultural/linguistic backgrounds" (Westby et al. 2002:238). Even though there has been elaborate academic discourse on the cultural differences of students' schooling experiences, the dominant paradigm still seems to be one where an assimilation into the mainstream is more highly prized than acknowledging multicultural diversity (cf. e.g. Souto-Manning 2013).

It is our assumption that such a preference for assimilation over diversity holds in particular for the areas of teaching and learning of narrative text structure. We hypothesise that the two aspects discussed here are instrumental to this trend. There seems to be a widespread understanding that canonical or mainstream (Anglo-American) story schemas and narrative text structure (or story grammar), which are perceived to be closest to event structure, are regarded as superior to alternative ways of narrative organisation. Moreover, this idea seems to be perpetrated by the dominance of narratives that adhere to this narrative text structure in the global space.

\section{Less canonical narrative text structures}

One main reason why a narrative text structure that is closely related to event structure is highly valued from an Anglo-American viewpoint can be found in the underlying worldview which places great emphasis on the chronological, linear order of events as well as the causal and temporal links between them. However, many story schemas and, consequently, narrative text structures do not adhere to this type of structure. For example, the underlying story schema might be a circular one where events are not ordered in a linear manner with clear temporalcausal relationships. A non-linear narrative text structure is common, for example, in 
Aboriginal English and Native American narratives. Sharifian (2002) observed that Aboriginal English narratives often revolve around a significant place or event. Furthermore, Highwater (1981) found that Native American narrative structures often have a spatial-causal episodic organisation which involves selecting, combining and recombining story chunks (or blocks of story information) to tell a story (Gough 1990). The order in which these story chunks are combined is not predetermined as "they may be in one order in one situation, but in a completely different order or even omitted in another situation" (Westby et al. 2002:240)

Consequently, as Cooley and Lujan (1982) found, Anglo-Americans often view narratives with a non-linear structure as disorganised and "rambling" (cf. Westby et al. 2002:241 for more detail). A similar comment was made by an audience member during the discussion session after an oral presentation of this article ${ }^{9}$. The commentator in question remarked that she had tried to read Northern Sotho folktales with her children but both she and her children had felt the storylines were "disconnected" and "made no sense".

These examples illustrate that the organisation of a narrative might be extremely different across cultures. Narratives can be structured according to implicit relationships between topics which, from an uninitiated point of view, may result in an apparent lack of across-topic cohesion (cf. Westby et al. 2002:241). In addition, narratives might also have different functions and display different narrative text structure elements across languages and cultures. In the following section we will focus our discussion on some of these characteristics as they occur in Southern African narratives.

\subsection{Some characteristics of Southern African narratives}

It is an oversimplification to say that we discuss characteristics of Southern African narratives; we do not want to imply that all Southern African narratives are the same or that all the characteristics we discuss are unique to Southern African narratives. Moreover, it is important to note that we only present a small selection of characteristics of Southern African narratives in this section. Our hope is that research on these characteristics will intensify due to the fact that African languages are currently being introduced as languages of teaching and learning on all levels of education in South Africa.

\subsubsection{Characteristic functions}

In the culture that we have termed "mainstream Anglo-American", it is part of a child's socialisation that caregivers and educators tell narratives and encourage the child to retell these, as well as giving narrative accounts of the child's daily activities. Both of these activities, however, may not necessarily be common in other cultures. Westby et al. (2002:240) explain that Native American children in the southwest of the USA are not expected to tell stories at all. Consequently, adults do not generally teach their children how to narrate and "children certainly would not be expected to tell a story to show what they know" (Westby et al. 2002:240). While we do not claim that parents do not engage in storytelling routines with their children in Southern African cultures, it is important to emphasise that children might not

\footnotetext{
${ }^{9}$ Presentation at the joint annual conference of the Linguistics Society of Southern Africa (LSSA), the Southern African Applied Linguistics Association (SAALA) and the South African Association for Language Teaching (SAALT), held from 1-4 July 2013 at the University of Stellenbosch.
} 
necessarily be familiar with telling narratives, which are inventive and/or about the children's own individual experiences, to adults.

Basso (1992) states that it is a given for Native American children that narratives should serve a specific purpose. The same has been said for Southern African narratives; Obiechina (1992:201-202) emphasises that Southern African narratives are communally shared and therefore transcend "the narrow limits of pure aestheticism and entertainment to encompass broad social and ethical purposes." Much along the same lines, Makgamatha (1991:7) argues that narratives in Northern Sotho play "a significant role in the daily lives of a particular social group in that they satisfy social and spiritual needs of that group". While amusement and entertainment are clearly also elements in Southern African narratives directed at children, the emphasis seems to be on the didactic functions instead (e.g. Makgamatha 1991:8). Narratives are considered essential for "[...] introducing young people to the customs of their people, [to] their beliefs and superstitions, their positive values, their ideas and ideals and everything that constitutes their moral and ethical view of the world" (Makgamatha 1991:9). Additionally, narratives are conceptualised as a means to establish and maintain conformity (Makgamatha 1991:11).

These characteristic functions of Southern African narratives may make it difficult for children who are exposed to a Southern African oral tradition to tell a narrative simply for the sake of telling a narrative, especially if the child is asked to relate a personal narrative as is often required of children in an academic context. While this aspect requires further research, we think that the specific functions of Southern African narratives may hinder certain groups of Southern African children in relating narratives in a school context. Moreover, we suspect that a feeling of alienation between the child and the narrative task might be corroborated by another characteristic of Southern African narratives, namely the element of performance.

\subsubsection{The element of performance}

Bearing in mind the element of performance in terms of the function of a narrative may illustrate why and how telling a narrative, as required in an educational context, might be misaligned with a Southern African child's narrative socialisation. All Southern African cultures have rich oral traditions that involve proficient storytellers, praise singers and oral historians. The various types of narratives and songs which they perform serve specific purposes and are directed at different audiences. There are male narrators who narrate specifically to male audiences and female narrators who narrate specifically to female audiences during or after initiation into adulthood, while narrators for young children seem to be predominantly (older) women.

Generally, the narrator closely interacts with the audience while drawing upon and evoking shared knowledge and moral values. Audience members usually have a very active role; sometimes they even intervene directly in the narrative, proffering comments or corrections or adding details (Obiechina 1992:217).

During performances of Chichewa narratives, the audience chants formulaic phases after every "content unit" (about one to two propositions in size) to signal that they follow the story ${ }^{10}$.

\footnotetext{
${ }^{10}$ For an illustration, see the two video clips on Nordic Africa Institute's website: http:// www.nai.uu.se/news/articles/2011/11/14/092041/.
} 
Certain speech communities of Northern Sotho tend to repeat the response form keleketla ${ }^{11}$ throughout the narrative whenever the speaker pauses. According to Makgamatha (1991:44), this audience interjection signals to the speaker that the audience members are listening and want the narrative to proceed. Such ritualised chants or interjections by the audience are common practice in many Southern African narrative performances. Westby et al. (2002:242) found similar practices for Native American narratives and they hypothesise that the children may be used to, and hence rely on, listener participation. However, this might generate problems for students in classroom environments, where teachers expect stories that are not embedded in a cultural, communal context and where listener participation is suppressed rather than encouraged.

It has also been hypothesised that the element of performance, in combination with listener participation, allows the "performing narrator" to de-emphasise cohesive textual features as there is an extensive common ground that is shared with the audience. Moreover, the narrator can rely on the audience to intervene should he/she lose track of the plot. Hence, linguistic features ensuring "stand-alone" meaningfulness of a narrative, such as explicit cohesive ties and context-independent antecedent-pronoun relationships, may be largely absent from a "performed narrative". In addition, the narrator's enactment of characters may serve as a nonlinguistic means to establish and maintain co-referential ties across the narrative. However, in the following quote, Nistov (2001:51) emphasises that the lack of cohesive structure in a narrative is disconcerting from a normative point of view that adopts the "canonical" narrative text structure (or story grammar) as the standard.

[...] [R]eferential management in decontextualised narrative discourse has been associated with cognitive and/or academic and literary skills. [...] The narrative in that respect is characterised as language use which requires from the learner to convey a coherent message with little available contextual support, in which all the information required for comprehension should be included in the words of the story.

Therefore, in essence, the presence of unambiguous cohesive and co-referential ties is one main criterion for the assessment of narratives in an educational context which might place children who are socialised in an oral storytelling tradition at a disadvantage.

\subsubsection{The role of repetitions}

Repetitions of both micro-structural elements (e.g. words, phrases) as well as macro-structural elements (e.g. a series of events comprised of episodes which are repeated several times throughout the narrative) are present in folk narratives all over the world. The function of repetition is to flesh out the narrative and to give it suspense. In "Western" and Anglo-American narratives, episodic repetitions are usually presented in sets of three. In contrast, narratives from native tribes in the southwest of the USA often have four episodes, which might be motivated by a reference to four elements such as the four cardinal directions. Moreover, narratives from native tribes in the Pacific Northwest may have five episodes and references to sets of five (Westby et al. 2002:242). Obiechina (1992:218) also emphasises the abundance of repetitions

\footnotetext{
${ }^{11}$ Makgamatha (1991:44) states that none of his informants could provide a lexical meaning for keleketla. The authors think that it might be related to the Shona word gweregeta meaning "speak up".
} 
as a stylistic element in Southern African folk narratives, specifically the repetition of key incidents and words, and states that repetitions of four or five are common. He adds that repetition may be employed to add emphasis in oral performance. Compare the example in (1a), which is easily identifiable as a stylistic element in an oral narrative, with that in (1b), which might be preferred in written narratives within an educational setting.

(1a) He waited and waited and waited.

(1b) He waited a long time.

Southern African folk narratives also typically contain a "core cliché", which may take the form of a song, a refrain, a chant or a saying. Core clichés are identified by Makgamatha (1991:54) as "[...] the most engaging, important, emotionally charged elements of the story, which are usually repeated at least once" (Makgamatha 1991:55). The element of repetition is also present in some of the formulaic openings and closings of folk narratives, as described in section 3.1.4.

\subsubsection{Opening and closing formulae}

\subsubsection{Opening formulae}

Like many other Southern African ethnic groups, the Tumbuka of Malawi initiate a storytelling session with riddles. Once the audience and the storyteller are ready, the narrative itself is initiated with the opening formula Kalekale kukaba... ('A long time ago there was...') (Makgamatha 1991:42). Makgamatha (1991:44) identifies a number of dialectal differences with regard to opening formulae in Northern Sotho narratives, some of which, as indicated earlier, contain repetitions; for example, $E$ (r)ile e (l)e nkano... ('There was a tale...'), E rile e le nonwane... ('There was a tale...'), E le e be nonwane... ('It was a tale...'), Ngano ngano... ('A tale, a tale...'), Nonwane, nonwane... ('A tale, a tale...'), Ile, ile... ('There was, there was...'). Similar opening formulae are used in most South African folk narratives, many of which locate the narrative in the remote past. In Setswana, one widely used opening formula is Ga twe e kile ya re ('It is said once upon a time') (Motshwari 1998:19) which is very similar to the isiZulu Kwasukasukela... ('There was once...'). Makgamatha (1991:46) argues that the opening formula has the function to introduce a fantasy world or fiction and "read[ies] the audience for a suspension of disbelief".

\subsubsection{Closing formulae}

Once you have opened the proverbial door to a fantasy world, you are obliged to close it; thus most folk narratives terminate with a formulaic ending. However, the way in which the ending is formulated differs considerably across language groups. Makgamatha (1991:47) explains that upon completion of the narrative, it is a common practice in various African countries to spit in the fire around which a narrative takes place. This signifies the "killing of the tale" so that ogres and supernatural beings cannot hunt the living, especially the young children" (Makgamatha 1991:47). The author elaborates further that in Northern Sotho the literal spitting is often replaced by the ideophone Mpho! which may be followed by the formula Sa mosela wa seripa! ('That which has a short tail!'). Less commonly used endings are Gi mafelelo a ngano ('It is the end of the tale') and E fedile ('It is ended') (Makgamatha 1991:45). Similarly, the closing formulae in Setswana are E felela fa ('It ends here') or Ke tsona tsotlhe ('That is all') (Motshwari 1998:20) which are similar to the traditional closing formulae in isiZulu Iyaphelake 
lapha ('It ends here') (Cannonici 1990:132) and Cosi cosi yaphela ('Little by little it comes to an end').

\subsubsection{Dialogues}

It has been widely established that dialogues are a prominent element in folktales which are rooted in oral tradition. Dialogues contribute to the performative nature of storytelling in that the narrator can enact different characters and lend them different voices; this is a globally used narrative strategy that adds interest to the narrative. Hence, the dialogue is a stylistic means of adding considerable amounts of entertainment and variation to an orally presented narrative which would otherwise be a lengthy monologue.

\subsubsection{Demotion of canonical narrative text structure elements}

In the same way that the beginning and the ending of a folk narrative are regulated by cultural tradition, the composition of the folk narrative also underlies predetermined rules. Makgamatha (1991:43) notes that "[...] the narrator feels bound to narrate [the folk narrative] according to socially prescribed rules with which the audience, who are also participants in the externalisation of this oral tradition, are familiar." Consequently, the freedom of composition is limited in oral literature.

Moreover, and even more significantly in the current context, narrative text structure elements that are considered to be essential in the "canonical" narrative text structure (or story grammar) are not necessarily part of the narrative text structure that underlies (Southern African) folk narratives. As discussed in section 2, "canonical" or mainstream Anglo-American narrative text structure is considered universally valid by some researchers (e.g. Mandler 1982) and, when compared with the educational settings of other countries, it appears to be as dominant in Southern African educational settings. In the following sections, we will argue that the two narrative structure elements of Setting and Internal Response/Reaction (Anderson and Evans 1996), which are considered essential in canonical narrative text structure models, are not necessarily essential in the narrative text structure underlying many folk narratives.

\subsubsection{Setting}

As previously mentioned, the setting is defined as " $[\mathrm{t}]$ he spatial and/or temporal location where story events take place; the introduction of the main characters, the protagonist, and the spatiotemporal context" (Griffith, Ripich and Dastoli 1987:541). The emphasis on having to present a setting might, however, be a function of the context in which a narrative evolves. In a narrative tradition, where narratives are perceived to "belong" to the audience as much as to the narrator and where the guiding principle of narrative discourse is that of a participatory narratoraudience engagement (cf. Westby et al. 2002:241), it might appear unnecessary to present a setting.

Indeed, many folk narratives do not elaborate on the spatio-temporal or social context in which the narrative unfolds. Traditional storytellers seem to be able to assume shared knowledge between themselves and their audience, and it seems to be rather the audience's responsibility to infer the meaning of the narrative or to engage with the storyteller where this should not be 
the case ${ }^{12}$. Such narrative practices form habituation patterns that may be carried over into other areas of oral and even written discourse. In line with this assumption, Leap (1986) reports that the Ute ${ }^{13}$ students he worked with tended to jump directly into storytelling without providing listeners with background information or reasons for their narratives. Thus it is important to be aware of the fact that it would not necessarily come naturally to a student to supply a setting for his/her narrative.

\subsubsection{Internal response/reaction}

Another element that appears to be habitually lacking in Southern African and other folk narratives is a description of the protagonist's internal response/reaction. Linguistic expressions that are categorised according to this element describe the main protagonist's reactions to initiating events, such as emotional responses, thoughts or intentions. The main function of an internal response/reaction is to motivate the protagonist to become active in order to achieve a goal. Examples of internal response/reaction include emotion verbs (e.g. cry, laugh), internal response adjectives (e.g. to be sad/happy/worried) and verbs relating to cognition (e.g. think, realise, notice).

The reason for the "omission" of this element might be similar to the one that Scollon and Scollon (1981) describe for the Athabaskan culture ${ }^{14}$. The Athabaskans consider it inappropriate to predict the future, to speak of one's plans or to assume that one knows the thoughts or feelings of others. In addition, in Southern African as well as in many other folktales, the emphasis is not so much on the protagonist as an individual with distinct feelings and motives that are grounded in their own affective state; rather, the protagonist becomes a schematised representative for a type of person. As Makgamatha (1991:43) explains, even main characters are mostly characterised in very simple terms with only those qualities which directly affect the story being mentioned.

\section{Influences of African narrative text structure in story retellings of Malawian children: A snapshot}

In the following sections, we report on preliminary empirical findings which, in our opinion, indicate that multilingual children in Malawi are influenced by their exposure to African folk narratives when they retell visually and aurally presented narratives in both Chichewa and English.

\subsection{Ethical approval}

The original study, from which the present study's data was extracted, was approved by the institutional ethical review committee of the University of KwaZulu-Natal (No.

\footnotetext{
${ }^{12}$ It may be argued that the omission of specific settings renders the moral lesson conveyed in the folktale more universally applicable than it would be if the tale were contextually "bound" to a specific location.

${ }^{13}$ The Ute people are an indigenous Native American people of the Great Basin, now living primarily in Utah and Colorado in the USA.

${ }^{14}$ Athabaskan or Athabascan (also Dene, Athapascan, Athapaskan) is a large group of indigenous peoples of North America, located in two main southern and northern groups in western parts of North America (US, Canada and Alaska).
} 
HSS/0246/012D). Formal written consent was obtained from the school principals, teachers, parents and children prior to the study.

\subsection{Participants}

The study's 127 participants were recruited from two schools in the city of Lilongwe, in the Lilongwe district of central Malawi. A parental questionnaire and interviews with teachers were used to exclude participants who do not speak Chichewa at home ${ }^{15}$ as well as children with language development or hearing problems. Of the participants, 69 attended a private school where they received their formal education in English. The remaining 58 participants attended a public school where they received their formal education predominantly in Chichewa (in this case, even though English is supposed to replace Chichewa from grade five onwards, the exams and homework assignments were set in English). The participants (64 female, 63 male) were between the ages of 10 and 12 (44 10-year-olds, 40 11-year-olds and 4312 -year-olds). Most of the children came from the same urban community, while some of the children who attended the public school came from rural areas. On average, the children who attended the private school came from a better socio-economic background than those who attended the public school $^{16}$.

Generally, the level of exposure to Chichewa narratives in the home environment was surprisingly high for all participants. Only seven of the 126 participants ${ }^{17}$ were not exposed to any storytelling in their home environment. Of the remaining participants, $107(90 \%)$ were either exposed to stories in Chichewa alone (51 participants) or to stories in both Chichewa and English (56 participants). Only 12 children were not exposed to any stories told in Chichewa at home, although 11 of these children were exposed to English stories ${ }^{18}$. Five children were exposed to stories in an additional language or additional languages. Of the participants, 114 $(90 \%)$ engaged in storytelling or retelling in Chichewa in their home environment (56 in Chichewa, 58 in both Chichewa and English). One of these children also told or retold stories in an additional language. Only 12 children did not tell or retell stories in Chichewa but in English only (9\%), or in both English and another language $(2 \%)$, or in another language altogether (1\%). Against this background, we hypothesise that there might be an influence of African narrative text structure on the children's retellings of aurally or visually presented narratives.

\footnotetext{
${ }^{15}$ Given the amount of multilingualism in Malawi it is not possible to restrict the data collection to participants who have only Chichewa as their home language. However, Chichewa serves as a lingua franca in Lilongwe and all participants use the language as one of their home languages. Chichewa is spoken by $70 \%$ of Malawi's population. Other languages include ChiYao (spoken by $10.1 \%$ ), Chitumbuka (9.5\%) as well as a number of smaller languages (Matiki 2009). Other languages used at home by our participants include Chitumbuka, Chitonga, ChiYao and English. One child is exposed to Chishona at home (a language mainly spoken in Zimbabwe).

${ }^{16}$ We have not yet run statistical correlation analyses to determine whether the demographic variables have an influence on the narrative text structures that the children employ. In the context of this article, this information is not necessary as we are focusing here on general trends.

${ }^{17}$ The total number of participants is 127 but one child's parent(s) did not answer this particular question in the parental questionnaire.

${ }^{18}$ Only one child's storytelling experiences were in a language other than Chichewa or English. In this case, the parents tell stories in Chishona at home. However, the child is fluent in Chichewa and more comfortable telling stories in Chichewa than in Chishona.
} 


\subsection{Materials}

Participants were exposed to either (i) two short films without any linguistic content, namely "The Little Mole and the Rocket"19 (Miler 1966) and "The Little Mole and the Radio"20 (Miler 1968), or (ii) verbal versions of the events depicted in the two film clips which were presented in either Chichewa or English. The film clips were chosen because of their accessibility ${ }^{21}$ and timeless popularity with an international audience of children (the film clips are popular television broadcasts in e.g. Central Europe, India, Japan, China and Russia). Our aim was to ensure that African children would be unfamiliar with the materials presented ${ }^{22}$.

Two verbal versions of each of the film clips "The Little Mole and the Rocket" (Miler 1966) and "The Little Mole and the Radio" (Miler 1968) were produced by native speakers of English and Chichewa, respectively. The English speaker produced an English narrative telling the stories of "The Little Mole and the Rocket" (Miler 1966) and "The Little Mole and the Radio" (Miler 1968); the Chichewa speaker produced a Chichewa narrative of the two film clips. All four narratives chronologically follow the series of events as they unfold in the film clips. Crucially, the Chichewa narratives were therefore not structured according to a Chichewa story schema. After the first versions of the four narratives were produced, the two verbal narratives that were produced from the same film clip were aligned with one another in terms of the events mentioned (i.e. if a particular event was mentioned in the Chichewa version, it was also mentioned in the English version) and the narrative text structure elements included (i.e. both verbal versions had the same number of narrative text structure elements). All narratives were subsequently read and assessed by a number of adult readers who are primary speakers of the two languages for coherence and "naturalness". The final versions were also read by teachers at the two schools to ensure that the vocabulary used was known to the children and that the level of complexity was in line with texts to which the children are commonly exposed. After the teachers confirmed that this was the case, the final versions were audio-recorded. For the audio recording, all narratives were read by an adult speaker who is bilingual in Chichewa and English. Pilot testing with Chichewa- and English-speaking children revealed that both Chichewa- and English-speaking children in the target age group could easily follow, and enjoy, both the visual and the aural presentations of the short narratives ${ }^{23}$.

\subsection{Procedures}

Narrative collection took place over several weeks. Participants were asked to generate narrative retellings after either viewing the wordless film clips or listening to the aural

\footnotetext{
${ }^{19}$ See http://www.myvideo.de/watch/2532807/Der_kleine_Maulwurf_und_die_Rakete .

${ }^{20}$ See http://www.myvideo.de/watch/7725206/Der_kleine_Maulwurf_und_das_Radio .

${ }^{21} \mathrm{We}$ used a DVD to present the stimulus material.

${ }^{22}$ The broader research project, from which this study stemmed, investigates text comprehension in bilingual Chichewa- and English-speaking children. It uses retellings after the presentation of film clips as a control condition in order to investigate retellings of aurally presented stories. Children in the original study also produced stories from a wordless picture book. The design idea of the original study was developed to elicit storytelling and retelling from stimulus material in different modalities, where the film clips were assumed to be the closest to an exposure to a real-world event and would therefore elicit retellings with the closest adherence to event structure. In our future research, we are going to use stimulus material that is specifically African in character.

${ }^{23}$ The stimulus materials can be made available upon request.
} 
presentations of the narratives. Narratives were collected by the second author and a local research assistant who both speak Chichewa as their primary language and who are both familiar with the elicitation procedure. Each child's narrations were recorded individually in a quiet room at one of the schools. Before the visual or aural presentation of the stories, the researcher/research assistant ensured that the child was comfortable and willing to participate in the study.

Aural presentations were either in English or Chichewa. Each child produced two narratives: elicitations of "The Little Mole and the Rocket" in Chichewa and English took place during the first session, and elicitations of "The Little Mole and the Radio" in both languages took place one week later during the second session. The participants were randomly assigned to one of the groups and, ultimately, six groups $\left(\mathrm{G}_{1}-\mathrm{G}_{6}\right)$ were obtained comprising approximately 22 participants each, as depicted in Table 3.

Table 3. The data presentation and elicitation process in overview ${ }^{24}$

\begin{tabular}{|l|c|c|}
\hline Presentation mode: Visual & \multicolumn{2}{|c|}{ Presentation mode: Aural } \\
\hline & Presentation in English & Presentation in Chichewa \\
\hline Retelling in Chich.G1/Eng.G2 & Retelling in Eng.G3/Chich.G4 & Retelling in Eng.G5/Chich.G6 \\
\hline \multicolumn{3}{|c|}{ One week gap } \\
\hline & Presentation in English & Presentation in Chichewa \\
\hline Retelling in Eng.G1/Chich.G2 & Retelling in Chich.G3/Eng.G4 & Retelling in Chich.G5/Eng.G6 \\
\hline
\end{tabular}

\subsection{Data analysis}

After the narratives were collected, each participant's narratives were transcribed. For each narrative, we assessed whether it contained those elements of African narrative text structures as described in sections 3.1.3 to 3.1.5, namely repetitions, opening formulae, closing formulae and dialogues. Moreover, we were interested to see whether the children's narratives contained the "canonical" narrative text structure (or story grammar) elements of Setting and Internal Response (Anderson and Evans 1996) which might be demoted or absent in African narrative text structures (see sections 3.1.5.1 and 3.1.5.2).

These narrative elements were first coded by one coder and subsequently coded by a second coder. In the case of the English narratives, the author coded the narratives first after which they were coded by the co-author; in the case of the Chichewa narratives, the co-author first coded the narratives and then a colleague, whose primary language ${ }^{25}$ is Chichewa, coded them.

\footnotetext{
${ }^{24}$ As previously mentioned, the current research stemmed from a larger research project with different objectives. Accordingly, the empirical study was not designed with the current research objective in mind.

${ }^{25}$ Here and throughout, we use the term "primary language" to indicate a speaker's native language which is at the same time his/her dominant language. We do not use the term "mother tongue" because many children's main caregiver is not their mother. Furthermore, the terms "home language" and "native language" do not capture the observation that many speakers have several home languages or native languages.
} 
For both sets of narratives, inter-coder agreement was high (97\% and 98\% respectively). Instances where coders disagreed were discussed and resolved.

Some children were unable to produce a narrative in either Chichewa or English. A total of seven participants from the private school (Kapita) could not produce retellings after they listened to aurally presented versions of either the "The Little Mole and the Rocket" or "The Little Mole and the Radio" stories (see Table 4 for an overview). Two participants could not produce English retellings after listening to the English audio stimulus and four participants could not produce Chichewa retellings after listening to the story presented to them in English (all six of these participants were more proficient in Chichewa than in English). One child was not able to produce a Chichewa retelling after listening to the "The Little Mole and the Rocket" in Chichewa. This child was more proficient in English than in Chichewa.

Table 4. Overview of the children who did not manage to produce a retelling from aurally presented stimulus material - Kapita (private school)

\begin{tabular}{|l|l|}
\hline Group 2 (Rocket) & 2 children (English retellings from English aural stories) \\
\hline Group 5 (Radio) & 2 children (Chichewa retellings from English aural stories) \\
\hline Group 5 (Rocket) & 2 children (Chichewa retellings from English aural stories) \\
\hline Group 3 (Rocket) & 1 child (Chichewa retelling from Chichewa aural stories) \\
\hline
\end{tabular}

There were significantly more participants (24) from the public school who struggled with (re)telling the stories than participants from the private school (7) who struggled to perform the same task (see Table 5 for an overview). In all of these cases, the children were more proficient in Chichewa than in English. A total of 15 children across a variety of conditions were unable to produce an English narrative, while nine participants found it impossible to produce a Chichewa narrative after listening to the aurally presented English story.

Table 5. Overview of the children who did not manage to produce a retelling from aurally presented stimulus material - Mphunchu (public school)

\begin{tabular}{|l|l|}
\hline Group 1 (a) (Radio) & 2 children (English narrations from film) \\
\hline Group 1 (a) Rocket & 3 children (English narrations from film) \\
\hline Group 2 (Radio) & 2 children (English retellings from English aural stories) \\
\hline Group 2 (Rocket) & 2 children (English retellings from English aural stories) \\
\hline Group 4 (Radio) & 2 children (English retellings from Chichewa aural stories) \\
\hline Group 4 (Rocket) & 4 children (English retellings from Chichewa aural stories) \\
\hline Group 5 (Radio) & 4 children (Chichewa retellings from English aural stories) \\
\hline Group 5 (Rocket) & 5 children (Chichewa retellings from English aural stories) \\
\hline
\end{tabular}

Twelve participants were not available for the second recording. This was due to a number of reasons relating to the fact that data collection took place towards the end of the school term 
(November 2012). For example, some parents removed their children from the private school after the first term because of a fee increase. In addition, there were high levels of absenteeism at both schools during the time period in which the second recording took place as the children and/or their parents thought there was nothing useful happening at the school after the final examinations. Some children had transferred to another school because their parents were no longer living in the locations close to the school. For example, some of the children at the public school had parents who were working as domestic workers or gardeners and lived at their employers' residences; consequently, a lot of employment insecurity resulted in frequent school transfers for their children. Overall, a total of 93 retellings in Chichewa and 103 retellings in English were obtained.

\subsubsection{The presence of repetitions}

Both the visually and aurally presented narratives contain repetitions of events. Moreover, the verbal narratives of the "The Little Mole and the Rocket" contains eight repetitions of word strings, both in the Chichewa and in the English versions, for example, "The pile grows bigger and bigger, pushing the bucket, higher and higher". The English and Chichewa versions of "The Little Mole and the Radio" each contain seven repetitions of word strings, for example, "Croak, goes the first frog. Croak, goes the second frog. Croak goes the third frog".

Even though the children used repetitions in their retellings, these were not typically a direct reflection of the repetitions which are present in the verbal stimulus material. For example, there was no verbatim rendering of the sentence "Croak, goes the first frog. Croak, goes the second frog. Croak goes the third frog." from the English version of the "The Little Mole and the Radio" in any of the 103 English retellings. Indeed, only six children mentioned the event at all, three of whom produced retellings from the visually presented material (examples E4, E5 and E6 in Table 4). Of the remaining three children, only two made use of repetition to retell the series of events, while one child summarised the event sequence.

Table 6. The "croaking frogs" repetition in the children's retellings

\begin{tabular}{|l|l|}
\hline Stimulus: & Croak, goes the first frog. Croak, goes the second frog. Croak goes the third frog. \\
\hline E1 & $\begin{array}{l}\text { "And ... and ... and the frog croak, the third frog, the second frog and they all } \\
\text { together they croak, and the last frog, and the ..." }\end{array}$ \\
\hline E2 & "The first one croaked, the other one croaked and the last one croaked again." \\
\hline E3 & "Then in the pond, he saw three frogs which croaked three times." \\
\hline E4 & $\begin{array}{l}\text { "Some frogs were jumping and croaking." } \\
\text { in the first frog croaked and went in the pond, the second frog croaked and went } \\
\text { together and went in the pond." }\end{array}$ \\
\hline E5 & "The frogs croak and croak and croak up and down, up and down." \\
\hline E6 &
\end{tabular}

Rather than mimicking existing repetitions from the stimulus material, some of the participants made use of repetitions in their own, idiosyncratic ways to add duration and intensity to their event descriptions. Therefore, the repetitions in the children's retellings were typically not the 
same repetitions that were present in the stimulus material. One child, for example, produced the utterance "the voice was going higher, high, high, high" which corresponds to the event description "each of them croaking a little higher than the last" in the aurally presented stimulus material. Moreover, some of the children were very imaginative in their use of repetitions, as is illustrated by the following example which was produced by a participant during an English retelling: "The rocket was saying 'tititi-tititi-tititi'. And after that the tunnel was also hearing 'tititi-tititi"',

Remarkably, repetitions were far more prominent in the Chichewa retellings than in the English retellings. In the Chichewa retellings, 55\% of the participants used repetitions, whereas only $28 \%$ of the participants used repetitions in the English retellings.

\subsubsection{The presence of opening formulae}

Neither the visually nor the aurally presented stimuli contained any opening formulae, while the film clips, as previously mentioned, did not contain any linguistic material. However, $37 \%$ of the participants inserted a traditional opening formula in their Chichewa retellings and 39\% of the participants inserted a traditional opening in their English retellings. The combination of a traditional opening and information recalled by the participants yielded interesting results; for example, one child started his/her retelling with "Once upon a time, there was a bucket".

\subsubsection{The presence of closing formulae}

As the film clips obviously did not contain closing formulae, we inserted traditional closing formulae into the Chichewa version (i.e. Nkhaniyi yathera pano) and the English version ("This is the end of the story") of the aurally presented narratives.

Surprisingly, a small percentage of the participants included a closing formula in their retellings. Furthermore, the participants typically did not reproduce the closing formula presented to them in the stimulus material. In the Chichewa retellings, only $33 \%$ of the participants inserted a traditional closing formula. In the English retellings, 31\% of the participants concluded their retelling with a traditional closing that would be particularly fitting for a Chichewa folktale (but not exclusively so), for example, that is the end or that is all.

\subsubsection{The presence of dialogues}

None of the aurally presented stories contained dialogues. However, slightly more than half of the Chichewa- and English-speaking participants included dialogues in their retellings, with $54 \%$ of the participants inserting dialogues into their Chichewa retellings, and $56 \%$ of the participants inserting dialogues into their English retellings.

\subsubsection{The presence of a setting}

The visually presented stories both commence with visuals of the scenery in which the little mole is situated, namely a beach ("The Little Mole and the Rocket") and a forest ("The Little Mole and the Radio"). The aurally presented versions of the two Little Mole stories begin with verbal descriptions of the setting. Accordingly, the English version of "The Little Mole and the Rocket" begins as follows: "There is a big pile of sand, an upside-down red bucket and a spade 
on the beach ...". Analogously, the Chichewa version of the same story starts with the translation equivalent of this sentence: "Pambali pa nyanja pali mulu wa ukulu wa mchenga, chidebe chofiira chotembenuzidwa, ndi fosholo ...". The English version of "The Little Mole and the Radio" begins with the following sentence to provide a setting: "A little mole lives in a forest with lots of trees, plants, flowers and even some mushrooms". The Chichewa version of the same story commences with a translation equivalent of this sentence: "Pali kanyama kenakake kotchedwa mfuko komwe kakukhala ku nkhalango yamitengo yambiri, maluwa, ndi bowa".

In their Chichewa retellings, only $23 \%$ of the participants included a setting. Furthermore, the presence of a setting was even less frequent in the English retelling as only $17 \%$ of the participants included a description thereof. In comparison, Acker (2012:80) found that South African children with either Afrikaans or English as their primary language predominantly inserted settings into their narratives elicited by a wordless picture book. Specifically, $55 \%$ of the five- to six-year-olds, $88 \%$ of the six- to seven-year-olds and $100 \%$ of the eight-and-a-half to nine-and-a-half year-olds in her sample began their narratives with a setting.

\subsubsection{The presence of internal reaction/response}

Overall, the children mentioned very few internal reactions/responses of the protagonist. The most frequently mentioned internal responses of the protagonist were kuwopa ('afraid/scared'), kusangalala ('happy'), kumva chisoni ('sad') and kudabwa ('surprised') (see Table 7). All of these adjectives correspond to a strong overt expression of an emotional response by the little mole in the film clips (e.g. the little mole crying profusely). Surprisingly, the retellings that were elicited by the film clips contained the smallest number of adjectives pertaining to the internal responses of the protagonist.

Hence, the aurally presented narratives triggered more adjectives describing internal responses than the film clips. The figures in Table 7 indicate that the children most often used internal response adjectives that were present in the verbal stimulus material (see the examples mentioned in the previous paragraph). As can be seen in Table 7, the Chichewa stimulus material contained a total of 22 internal response adjectives, while the English stimulus material contained a total of 19 . However, the participants on average mentioned as few as 0.54 internal response adjectives per Chichewa retelling and 0.89 internal response adjectives per English retelling. This shows that the vast majority of the participants do employ at least one internal response adjective.

In other words, the total number of possible imitations of the internal response adjectives from the stimulus material in the Chichewa retellings is $93 \times 22$ adjectives, therefore amounting to a total of 2046 instances. However, the children's verbalisations contained a mere 51 internal response adjectives (2.49\%). In comparison, in the English retellings the children used 92 internal response adjectives, which is only $5.25 \%$ of the total number of possible imitations of the internal response adjectives contained in the stimulus material (i.e. $103 \times 17$ adjectives amounting to a total of 1751 possible imitations of internal response adjectives). 
Table 7. Frequency of internal response/reaction of the protagonist mentioned in the participants' retellings compared with occurrences of the internal response/reaction adjectives in the stimulus material (absolute numbers)

\begin{tabular}{|l|c|c|c|c|}
\hline Internal response/reaction adjectives & $\begin{array}{c}\text { Chichewa } \\
\text { Stories }\end{array}$ & $\begin{array}{c}\text { Chichewa } \\
\text { Retellings } \\
(\mathrm{N}=93)\end{array}$ & $\begin{array}{c}\text { English } \\
\text { Stories }\end{array}$ & $\begin{array}{c}\text { English } \\
\text { Retellings } \\
(\mathrm{N}=103)\end{array}$ \\
\hline Kuwopa $\sim$ afraid/scared & 7 & 7 & $0 / 6$ & $16 / 12$ \\
\hline Kukwiya $\sim$ angry & 1 & 9 & 1 & 4 \\
\hline Kukhumudwa $\sim$ disappointed & 0 & 3 & 0 & 2 \\
\hline Kusangalala $\sim$ happy & 3 & 42 & 2 & 23 \\
\hline Kumva chisoni $\sim$ not happy/sad & 5 & 1 & $0 / 8$ & $3 / 28$ \\
\hline Kupepukidwa $\sim$ relieved & 0 & 0 & 0 & 1 \\
\hline Kudabwa $\sim$ surprised & 5 & 22 & 2 & 1 \\
\hline Kudandaula $\sim$ worried & 1 & 7 & 0 & 2 \\
\hline Total & 22 & 51 & 19 & 92 \\
\hline
\end{tabular}

The figures presented in Table 7 indicate that the language in which the participants retold the narratives has an effect on the frequency with which they used internal response adjectives. Overall, the participants in the English retellings used more internal response adjectives and also made more statements pertaining to the protagonist's thought processes. Derivations of the verb to think were employed 13 times in the English retellings compared with only three occurrences in the Chichewa retellings. However, none of the aurally presented English narratives contained any form of this verb, whereas the Chichewa stimulus material contained two occurrences of the Chichewan equivalent -ganiz-.

Finally, it is remarkable that the frequency with which the children mention individual internal response adjectives seems to vary according to the language in which they encode the stimulus material. While kusangalala ('happy') has a comparably high frequency in both languages, kusangalala appears in the Chichewa retellings almost twice as often as happy does in the English ones (42 in comparison to 23). In contrast, kumva chisoni appears only once in the Chichewa retellings while not happy/sad appears 31 times in the English retellings. Similarly, kuwopa was mentioned seven times in the Chichewa retellings while afraid/scared appeared 28 times in the English retellings. Lastly, kudabwa appeared more frequently in the Chichewa versions than surprised did in the English ones (22 in comparison to 1). At first glance, the latter finding seems attributable to the fact that kudabwa was mentioned five times in the Chichewa stimulus material, while surprise only appeared twice in the English stimulus material. However, kusangalala and happy were only mentioned three times and two times respectively, in the respective stimulus materials, and yet kusangalala was produced 42 times and happy only 23 times in the retellings. Therefore, there may be additional factors at play here, other than mere presence in the stimulus material, with regard to preferences in choosing to verbalise a particular internal response adjective in a particular language.

Acker (2012:57) found that 50\% of her five- to six-year-old, $65 \%$ of her six- to seven-year-old, and $68 \%$ of her eight-and-a-half to nine-and-a-half year-old South African English- or 
Afrikaans-speaking participants described the protagonist's internal responses ${ }^{26}$. Acker $(2012: 57)$ elaborates in the following quote:

Although not statistically significant, an increase in the use of I[nternal] $\mathrm{R}$ [esponse] across the age groups was observed $\chi^{2}(2, \mathrm{~N}=62)=1.62, \mathrm{p}=.44571$. This finding is supported by the findings of Roth and Spekman (1986), who found that only after children enter school at the age of 6 do they learn to tell stories pertaining to the "inner life" of characters (reflected by IR elements in their narratives).

Our participants, who are between the ages of 10 and 12, do not seem to focus on the verbalisation of internal responses which is, in fact, a canonical story grammar element.

\subsection{Summary of the findings}

In sections 4.1 to 4.5 , we presented empirical findings that indicate a possible influence of traditional narrative text structure on Chichewa and English retellings by 10- to 12-year-old Malawian children. Our aim was to highlight general trends and, as such, we did not trace individual children nor did we unpack the data according to possible influences of the variables of age, social background, school type and presentation mode of the stimulus (visual vs. aural).

Specifically, we hypothesised that the retellings of our participants would employ a substantial amount of repetitions, opening and closing formulae, and dialogues, all of which play a prominent role in African narrative text structure. In contrast, we also hypothesised that our participants would not use the two canonical text structure elements of Setting and Internal Reaction/Response (Anderson and Evans 1996) as often as would be expected from children of their age group. Norbury and Bishop (2003) and Owens (2010) suggest that typicallydeveloping children generally produce all canonical story grammar elements by the age of nine.

Our findings show that our participants used repetitions in idiosyncratic ways which did not directly imitate the use of repetitions in the stimulus material. Overall, more of the Chichewa retellings than the English ones contained repetitions (55\% vs. 28\% respectively). Opening formulae and closing formulae did not feature prominently in the participants' retellings (percentages range from $31 \%$ to $39 \%$ across the two languages). However, $37 \%$ of the participants inserted a traditional opening in their Chichewa retellings and $39 \%$ inserted a traditional opening in their English retellings, even though the stimulus materials of both languages did not contain traditional opening formulae. In addition, the participants used a wider range of traditional closing formulae than those that were present in the stimulus material. More than half the participants included dialogues in their retellings irrespective of the language (54\% in Chichewa and 56\% in English), even though there were none present in the stimulus material. These findings indicate that the participants have a tendency to employ elements of African narrative text structures in their retellings.

\footnotetext{
${ }^{26}$ It is not quite clear which linguistic expressions that refer to internal responses Acker (2012) considered in her analysis. We used internal response adjectives and the verb to think as these were present in the stimulus material.
} 
We also found that only $23 \%$ of the Chichewa retellings and $17 \%$ of the English retellings contained a setting (section 4.5.5), even though a setting was provided in the stimulus material. Furthermore, the participants used a small amount of internal response adjectives in both languages. Importantly, the latter trend was particularly prominent in the Chichewa retellings. Therefore, the findings support our second hypothesis, namely that the participants would exclude these canonical story structure elements quite often. An additional finding is that the participants verbalised afraid/scared and unhappy/sad with a higher frequency in English than the corresponding translation equivalents in Chichewa (i.e. kuwopa and kumva chisoni respectively). Furthermore, they used kusangalala and kudabwa with a much higher frequency in Chichewa than the corresponding translation equivalents in English (i.e. happy and surprised respectively).

Overall, our findings indicate that children who are exposed to traditional African storytelling during socialisation might be influenced in their storytelling practices by a narrative text structure that is different from the "canonical" narrative text structure (or story grammar) widely employed in educational settings. This observation holds for both languages but the influence of African narrative text structure seems to be somewhat stronger in the Chichewa retellings as they contain more repetitions and fewer internal response adjectives than the English ones.

\section{Concluding remarks}

With the current article, we hope to contribute to an awareness of the importance of contrastive rhetoric in a Southern African context. We believe that it is mandatory to acknowledge different narrative practices and negotiate these in educational settings on all levels of academic teaching and learning. There is a danger of demotivating our students and setting them up for failure if we do not understand that they come with rich, albeit culture-specific, repertoires of narrative practices that include their own constraints (e.g. the (non-)use of internal response expressions). Due to spatial limitations, there are many aspects that we were not able to address here.

One core finding is that the ways of assessing narrative performance must appear "unnatural" to Southern African children who are used to experiencing narratives as performances and storytelling as an intense interaction between storyteller and audience. Listening to a narrative without being able to comment and participate in the process takes away a multimodal encoding experience that may serve as a mnemonic aid. Retelling a narrative by way of a monologue may feel alien and unnerving yet this is how we assess narrative abilities both in educational and scientific settings (the research presented in this article is no exception).

The teaching and learning of African languages themselves, specifically for (a hopefully growing number of) non-African second-language learners, should ideally be based on a contrastive rhetoric approach so that the learners are able to navigate the narrative space of the African languages in appropriate ways.

In order to achieve these goals, and also to preserve the rich repertoire of oral traditions, a larger body of research is required on narrative practices in African languages and on African narratives themselves. One of the shortcomings of this article is that comparative data is not easily available. Moreover, as previously mentioned, the current study stemmed from a larger research project on text comprehension in bilingual children and was not designed to investigate 
the presence of African narrative text structure. As such, we are currently developing an empirical study with this specific aim in mind.

\section{Acknowledgements}

We wish to thank the audience of our oral presentation of this research at the 2013 annual joint conference of the Linguistics Society of Southern Africa, the Southern African Applied Linguistics Association and the South African Association for Language Teaching for their encouragement and comments. A travel grant from the University of KwaZulu-Natal that enabled the second author to travel to this conference is gratefully acknowledged. We are indebted to two anonymous reviewers who added valuable aspects to which we have attended to the best of our ability, and our special thanks go to Lauren Onraët who diligently edited our drafts. All remaining errors are our own. Finally, we want to thank the teachers, parents and, in particular, the children, who not only had to listen to but also had to produce monologues during their participation in this research.

\section{References}

Acker, T. 2012. The patterns of development in generated narratives of a group of typically developing South African children aged 5 to 9 years. Unpublished MA dissertation. Stellenbosch: University of Stellenbosch.

Anderson, K. and C. Evans. 1996. The development of the Canonical Story Grammar Model and its use in the analysis of beginning reading computer stories. Reading Improvement 33(1): $2-15$.

Barnitz, J.G. 1986. Toward understanding the effects of cross-cultural schemata and discourse structure on second language reading comprehension. Journal of Reading Behavior 18(2): 95116.

Basso, E.B. 1992. Contextualization in Kalapalo narratives. In A. Duranti and C. Goodwin (eds.) Rethinking context: Language as an interactive phenomenon. Cambridge: Cambridge University Press. pp. 253-270.

Bechger, T.M., E. van Schooten, C. de Glopper and J.J. Hox. 1998. The validity of international surveys of reading literacy: The case of the IEA reading literacy study. Studies in Educational Evaluation 24: 99-125.

Berman, R.A. and D.I. Slobin. 1994. Relating events in narrative: A crosslinguistic developmental study. Hillsdale, NJ: Lawrence Erlbaum Associates.

Botting, N.F., B. Faragher, Z. Simkin, E. Knox and G. Conti-Ramsden. 2001. Predicting pathways of specific language impairment: What differentiates good and poor outcome? Journal of Child Psychology and Psychiatry 42(8): 1013-1020.

Bower, G.H., J.B. Black and T.J. Turner. 1979. Scripts in memory for text. Cognitive Psychology 11(2): 12-177. 
Brewer, W.F. 1984. The story schema: Universal and culture-specific properties. Technical Report No. 322. Champaign, Illinois: University of Illinois at Urbana-Champaign: Center for the Study of Reading.

Brewer, W.F. and E.H. Lichtenstein. 1980. Event schemas, story schemas and story grammars. Technical Report No. 197. Champaign, Illinois: University of Illinois at Urbana-Champaign: Center for the Study of Reading.

Brooks, R.A. 1991. Intelligence without representation. Artificial Intelligence 47(1-3): 139159.

Brownstein, A.L. and S.J. Reed. 2007. Situation models and memory: The effects of temporal and causal information on recall sequence. Memory 15(7): 730-745.

Bungera, A., A. Papafragoua and J.B. Trueswell. 2013. Event structure influences language production: Evidence from structural priming in motion event description. Journal of Memory and Language 69(3): 299-323.

Cannonici, N.N. 1990. Oral studies in South Africa. Unpublished MA dissertation. Durban: University of Natal.

Carnine, D. and D. Kinder. 1985. Teaching low-performing students to apply generative and schema strategies to narrative and expository material. Remedial and Special Education 6(1): 20-30.

Chafe, W.L. 1980. The pear stories: Cognitive, cultural, and linguistic aspects of narrative production. In R.O. Freedle (ed.) Advances in discourse processes: Vol. III. Norwood, NJ: Ablex. pp. 275-299.

Clark, A. 2001. Mindware. New York and Oxford: Oxford University Press.

Cooley, D. and P. Lujan. 1982. A structural analysis of speeches by Native Americans. In F. Barkin, E.A. Brandt and J. Ornstein-Galicia (eds.) Bilingualism and language contact: Spanish, English, and Native American languages. New York: Teachers College Press. pp. 80-92.

Cowley, S.J. 2009. Distributed language and dynamics. Pragmatics and Cognition 17(3): 495507.

Curenton, S.M. and L.M. Justice. 2004. African American and Caucasian preschoolers' use of decontextualized language: Literate language features in oral narratives. Language, Speech, and Hearing Services in Schools 35(3): 240-252.

D'Andrade, R. 1995. The development of cognitive anthropology. Cambridge: Cambridge University Press.

Dickinson, D. and P. Tabors (eds.) 2001. Beginning literacy with language: Young children learning at home and school. Baltimore, MD: Paul H. Brookes. 
Dimino, J., R. Gersten, D. Carnine and G. Blake. 1990. Story grammar: An approach for promoting at-risk secondary students' comprehension of literature. The Elementary School Journal 91(1): 19-32.

Fagella-Luby, M., J.S. Schumaker and D.D. Deshler. 2007. Embedded learning strategy instruction: Story-structure pedagogy in heterogeneous secondary literature classes. Learning Disability Quarterly 30(2): 131-147.

Feltis, B.B., M.B. Powella, P.C. Snow and C.H. Hughes-Scholes. 2010. An examination of the association between interviewer question type and story-grammar detail in child witness interviews about abuse. Child Abuse \& Neglect 34(6): 407-413.

Fitzgerald, J. and D.L. Spiegel. 1983. Enhancing children's reading comprehension through instruction in narrative structure. Journal of Reading Behavior 15(1): 1-17.

Gardill, M.C. and A.K. Jitendra. 1999. Advanced story map instruction: Effects on the reading comprehension of students with learning disabilities. Journal of Special Education 33(1): 2-17.

Gersten, R., L.S. Fuchs, J.P. Williams and S. Baker. 2001. Teaching reading comprehension strategies to students with learning disabilities: A review of research. Review of Educational Research 71(2): 279-320.

Girolametto, L., M. Wiigs, R. Smyth, E. Weitzman and P. Pearce. 2001. Children with a history of expressive language delay: Outcomes at 5 years of age. American Journal of SpeechLanguage Pathology 10: 358-369.

Gough, D. 1990. The principle of relevance and the production of discourse: Evidence from Xhosa folk narrative. In B.K. Britton and A.D. Pellegrini (eds.) Narrative thought and narrative language. Hillsdale, NJ: Lawrence Erlbaum. pp. 199-217.

Gregory, G.A. 1993. The texture of essays written by basic writers: Diné and Anglo. Unpublished $\mathrm{PhD}$ dissertation. University of New Mexico.

Griffey Jr., Q.L., N. Zigmond and G. Leinhardt. 1988. The effects of self-questioning and story structure training on the reading comprehension of poor readers. Learning Disability Quarterly 4(1): 45-51.

Griffith, P.L., D.N. Ripich and S.L. Dastoli. 1987. Story structure, cohesion, and propositions in story recalls by learning-disabled and nondisabled children. Journal of Psycholinguistic Research 15(6): 539-555.

Gurney, D., R. Gersten, J. Dimino and D. Carnine. 1990. Story grammar: Effective literature instruction for high school students with learning disabilities. Journal of Learning Disabilities 23(6): 335-342.

Habel, C. and H. Tappe. 1999. Processes of segmentation and linearization in describing events. In R. Klabunde and C. von Stutterheim (eds.) Representations and processes in language production. Wiesbaden: Deutscher Universitäts-Verlag. pp. 117-152. 
Highwater, J. 1981. The primal mind: Vision and reality in Indian America. New York: Harper \& Row.

Holland, D. and M. Cole. 1995. Between discourse and schema: Reformulating a culturalhistorical approach to culture and mind. Anthropology and Education Quarterly 26(4): 475490.

Idol, L. and V.J. Croll. 1987. Story mapping training as a means of improving reading comprehension. Learning Disability Quarterly 10(3): 214-229.

Kintsch, W. 2004. The Construction-Integration model of text comprehension and its implications for instruction. In R. Ruddell and N. Unrau (eds.) Theoretical models and processes of reading. Newark, DE: International Reading Association. pp. 1270-1328.

Labov, W. 1972. Language in the inner city. Philadelphia: University of Philadelphia Press.

Leap, W. 1986. Assumptions and strategies in guiding mathematics problem solving by Ute students. In R. Cocking and J. Mestre (eds.) Linguistic and cultural influences on learning mathematics. Hillsdale, NJ: Lawrence Erlbaum. pp. 161-186.

Levelt, W.J. 1982. Linearization in describing spatial networks. In S. Peters and E. Saarinen (eds.) Processes, beliefs, and questions: Essays on formal semantics of natural language and natural language processing. Dordrecht: D. Reidel: pp. 199-220.

Makgamatha, P.M. 1991. Characteristics of the Northern Sotho folktales: Their form and structure. Johannesburg and Cape Town: Perskor.

Makoe, P. and C. McKinney. 2009. Hybrid discursive practices in a South African multilingual primary classroom: A case study. English Teaching: Practice and Critique 8(2): 80-95.

Malcolm, I.G. and F. Sharifian 2002. Aspects of Aboriginal English oral discourse: An application of cultural schema theory. Discourse Studies 4(2): 169-181.

Mandler, J.M. 1978. A code in the node: The use of story schema in retrieval. Discourse Processes 1(1): 14-35.

Mandler, J.M. 1982. Recent research on story grammars. In J.-F. Le Ny and W. Kintsch (eds.) Language and comprehension. Amsterdam: North-Holland Publishing Company. pp. 207-218.

Mandler, J.M. 1983. Representation. In P. Mussen (ed.) Handbook of child psychology, Vol. III. New York: John Wiley and Sons. pp. 420-494.

Mandler, J.M. 1984. Stories, scripts, and scenes: Aspects of schema theory. Hillsdale, NJ: Lawrence Erlbaum Associates.

Mandler, J.M. and M. DeForest. 1979. Is there more than one way to recall a story? Child Development 50(3): 886-889. 
Mandler, J.M. and N.S. Johnson. 1977. Remembrance of things parsed: Story structure and recall. Cognitive Psychology 9(1): 111-151.

Mandler, J.M., S. Scribner, M. Cole and M. De Forest. 1980. Cross-cultural invariance in story recall. Child Development 51(1): 19-26.

Manhardt, J. and L. Rescorla. 2002. Oral narrative skills of late talkers at ages 8 and 9. Applied Psycholinguistics 23(1): 1-21.

Matiki, A.J. 2009. Re-examining language shift cases in Malawi in the context of Fishman's GIDS. Journal of Multilingual and Multicultural Development 30(6): 535-546.

Mayer, M. 1969. Frog, where are you? New York: Dial Press.

Motshwari, J.J. 1998. Magic and its significance in Tswana folktales. Unpublished MA dissertation. Johannesburg: Rand Afrikaans University.

Nistov, I. 2001. Reference continuation in L2 narratives of Turkish adolescents in Norway. In L. Verhoeven and S. Strömqvist (eds.) Narrative development in a multilingual context. Amsterdam: John Benjamins. pp. 51-86.

Norbury, C.F. and D.V.M. Bishop. 2003. Narrative skills of children with communication impairments. International Journal of Communication Disorders 38(3): 287-313.

Obiechina, E. 1992. Narrative proverbs in the African novel. Oral Tradition 7(2): 197-230.

Olson, M.W. and T.C. Gee. 1988. Understanding narrative: A review of story grammar research. Childhood Education 64(5): 302-306.

Ouellette, G., L. Dagostino and J. Carifio. 1998. The relationship of children's expectations for structure in story to their knowledge of literature and their reading ability. Reading Improvement 35(3): 98-113.

Owens, R.E. 2010. Language disorders: A functional approach to assessment and intervention. London: Pearson.

Parke, T. 2001. Words and turns: Bilingual and monolingual children construct a story. Linguistics and Education 12(4): 409-430.

Pianesi, F. and A.C. Varzi. 2000. Events and event talk: An introduction. In J. Higginbotham, F. Pianesi and A.C. Varzi (eds.) Speaking of events. Oxford: Oxford University Press. pp. 3-47.

Radvansky, G.A. and D.E. Copeland. 2006. Situation models and retrieval interference: Pictures and words. Memory 14(5): 614-623.

Rand, M. K. 1984. Story schema: Theory, research and practice. The Reading Teacher 37(4): 377-382. 
Raskin, D.C. and P.W. Esplin. 1991. Statement validity assessment: Interviewing procedures and content analysis of children's statements of sexual abuse. Behavioral Assessment 13(3): 256-291.

Rice, G.E. 1980. On cultural schemata. American Ethnologist 7(1): 152-171.

Rumelhart, D.E. 1975. Notes on a schema for stories. In D.G. Bobrow and A. Collins (eds.) Representation and understanding: Studies in cognitive science. New York: Academic Press. pp. 211-236.

Scollon, R. and S.B.K. Scollon. 1981. Narrative, literacy and face in interethnic communication. Norwood, NJ: Ablex.

Shapiro, L.R. and J.A. Hudson. 1991. Tell me a make-believe story: Coherence and cohesion in young children's picture-elicited narratives. Developmental Psychology 27(6): 960-974.

Sharifian, F. 2001. Schema-based processing in Australian speakers of Aboriginal English. Language and Intercultural Communication 1(2): 120-134.

Sharifian, F. 2002. Chaos in Aboriginal English discourse. In A. Kirkpatrick (ed.) Englishes in Asia: Communication, identity, power and education. Melbourne: Language Australia. pp. 125141.

Shore, B. (1996). Culture in mind: Cognition, culture, and the problem of meaning. Oxford: Oxford University Press.

Short, E.J. and E.B. Ryan. 1984. Metacognitive differences between skilled and less skilled readers: Remediating deficits through story grammar and attribution training. Journal of Educational Psychology 76(2): 225-235.

Singer, H. and D. Donlan. 1982. Active comprehension: Problem-solving schema with question generation for comprehension of complex short stories. Reading Research Quarterly 17(2): 166-185.

Slobin, D. 2004. The many ways to search for a frog: Linguistic typology and the expression of motion events. In S. Strömqvist and L. Verhoeven (eds.) Relating events in narrative, Vol. 2: Typological and contextual perspectives. Mahwah, NJ: Lawrence Erlbaum Associates. pp. 219-257.

Soodla, P. and E. Kikas. 2010. Macrostructure in the narratives of Estonian children with typical development and language impairment. Journal of Speech, Language, and Hearing Research 53(5): 1321-1333.

Souto-Manning, M. 2013. Competence as linguistic alignment: Linguistic diversities, affinity groups, and the politics of educational success. Linguistics and Education 24(3): 305-315. 
Stein, N.L. and C.G. Glenn. 1979. An analysis of story comprehension in elementary school children. In R. Freedle (ed.) New directions in discourse processing. Norwood, NJ: Ablex. pp. 53-120.

Stein, N.L. and T. Nezworski. 1978. The effects of organization and instructional set on story memory. Discourse Processes 1(2): 177-193.

Strauss, C. and N. Quinn. 1997. A cognitive theory of cultural meaning. New York: Cambridge University Press.

Strömqvist, S. and L. Verhoeven (eds.) 2004. Relating events in narrative, Vol. 2: Typological and contextual perspectives. Mahwah, NJ: Lawrence Erlbaum Associates.

Tannen, D. 1980. A comparative analysis of oral narrative strategies: Athenian Greek and American English. In W. Chafe (ed.) The pear stories: Cognitive, cultural and linguistic aspects of narrative production. Norwood, NJ: Ablex. pp. 51-87.

Tappe, H. and C. Habel. 1998. Verbalization of dynamic sketch maps: Layers of representation in the conceptualization of drawing events. Proceedings of the twentieth annual conference of the Cognitive Science Society (COGSCI 1998), 1-4 August 1998, University of Wisconsin, Madison, WI.

Thorndyke, P.W. 1977. Cognitive structures in comprehension and memory of narrative discourse. Cognitive Psychology 9(1): 77-110.

Van Dijk, T.A. and W. Kintsch. 1983. Strategies of discourse comprehension. New York: Academic Press.

Westby, C., C. Moore and R. Roman. 2002. Reinventing the enemy's language: Developing narratives in Native American children. Linguistics and Education 13(2): 235-269.

Whaley, J.F. 1981. Readers' expectations for story structures. Reading Research Quarterly 1(9): 107-111.

Wyer Jr., R.S. 2004. Social comprehension and judgment: The role of situation models, narratives, and implicit theories. Mahwah, NJ: Lawrence Erlbaum Associates.

Zwaan, R.A. and G.A. Radvansky. 1998. Situation models in language comprehension and memory. Psychological Bulletin 123(2): 162-185. 